Chronic Obstructive Pulmonary Diseases: Journal of the COPD Foundation

\title{
Review
}

\section{Celebration of the 50-Year Anniversary of the National Heart, Lung, and Blood Institute Division of Lung Diseases: A Half-Century of Landmark Clinical Trials}

\author{
Robert A. Wise, $\mathrm{MD}^{1}$ Jerry A. Krishnan, $\mathrm{MD}^{2}$
}

\begin{abstract}
The National Institutes of Health (NIH)-National Heart, Lung, and Blood Institute's (NHLBI) Division of Lung Diseases is celebrating its 50th anniversary. On this occasion, we are reviewing the major landmark clinical trials that were initiated by the NHLBI's Division of Lung Disease and that have had substantial impact on our understanding of chronic obstructive pulmonary disease (COPD) and how it is best treated. Although some of these trials did not show hypothesized treatment benefits for COPD, they have enabled clinicians to provide care for individuals with COPD relying on the most rigorous evidence. The 5 trials that are reviewed here are: the Intermittent Positive Pressure Breathing Trial, the Nocturnal Oxygen Treatment Trial, the Lung Health Study, the National Emphysema Treatment Trial, and the Long-term Oxygen Treatment Trial. These clinical trials have not only set the standards for COPD care but have served as models for the state-of-the-art conduct of clinical research in COPD.
\end{abstract}

Abbreviations: National Institutes of Health, NIH; National Heart, Lung, and Blood Institute, NHLBI; Division of Lung Diseases, DLD; chronic obstructive pulmonary disease, COPD; intermittent positive pressure breathing, IPPB; forced expiratory volume in 1 second, FEV $\mathbf{1}$; forced vital capacity, FVC; modified Medical Research Council dyspnea scale, mMRC; body weight, obstruction, dyspnea, exercise capacity score, BODE; age, dyspnea, obstruction score, ADO; Medical Research Council, MRC; Nocturnal Oxygen Treatment Trial, NOTT; positive pressure of oxygen, $\mathbf{P a O}_{2}$; Centers for Medicare and Medicaid Services, CMS; Lung Health Study, LHS; lung volume reduction surgery, LVRS; National Emphysema Treatment Trial, NETT; Long Term Oxygen Treatment Trial, LOTT

Funding Support: Not applicable

Date of Acceptance: October 7, 2019

Citation: Wise RA, Krishnan JA. Celebration of the 50-year anniversary of the National Heart, Lung, and Blood Institute Division of Lung Diseases: a half-century of landmark clinical trials. Chronic Obstr Pulm Dis. 2019;6(4):359-370. doi: https://doi.org/10.15326/ jcopdf.6.4.2019.0157

1 Johns Hopkins University School of Medicine, Baltimore, Maryland

2 University of Illinois College of Medicine, Chicago

\section{Address correspondence to:}

Robert A. Wise, MD

Johns Hopkins University School of Medicine

5501 Hopkins Bayview Circle

Baltimore, MD 21224

Phone: 410-550-0545

Email: rwise@jhmi.edu

\section{Keywords:}

COPD; chronic obstructive pulmonary disease; clinical trials; lung volume reduction surgery; oxygen therapy; smoking cessation; positive pressure breathing 


\section{Introduction}

On the celebration of the 50th anniversary of the National Heart, Lung, and Blood Institute's (NHLBI) Division of Lung Diseases (DLD) it is appropriate to review the major contributions of the Division in the management of chronic obstructive pulmonary disease (COPD) in terms of major clinical trials. This article will review the 5 major multicenter clinical trials that the NHLBI has initiated and sponsored. These trials have changed the landscape of COPD and have set the standards by which clinical trials are conducted presently. This review will review the landmark clinical trials that have been initiated by the NHLBI and the DLD and will not include the dozens of investigator-initiated research that have also moved the field forward and the substantial contributions from clinical trial networks and research groups that have been supported by the NHLBI. Typically, these trials have addressed practical concerns that have been raised by the pulmonary academic and clinical community. Often, the hypotheses tested in these trials were the product of a formal workshop conducted by NHLBI, followed by a formal request for applications or a formal request for proposals.

NHLBI-initiated clinical trials have been characterized by the highest levels of scientific integrity and state-of-the-art conduct and organization. The typical trial has been organized around a data coordinating center and a steering committee composed of the individual study site principal investigators. The steering committee has been led by a study chair, appointed by the NHLBI, who may or may not be one of the study investigators. The safety of participants and the quality of the data have been subject to review and oversight of a data and safety monitoring committee that reports to the NHLBI. A project officer works closely with the study leadership to ensure that scientific goals of the trial are met. In recent years there has been involvement of clinical trial specialists who are experienced individuals in the day-to-day management of clinical research. These clinical trial specialists assist the project officer in the daily issues that arise in the conduct of clinical research and act as liaison with the investigators. Over the years, the methods and structure of clinical trials conducted by the NIHLBI have become the standard by which COPD clinical research is conducted.

\section{Intermittent Positive Pressure Breathing Trial}

In the 1960s and 70s, it was common practice to administer bronchodilators or saline with intermittent positive pressure breathing (IPPB) devices. The theoretical benefit of such devices was based on the idea that it was possible to disperse aerosols more effectively with positive pressure than with spontaneous breathing. Some health care establishments provided such treatments to COPD patients as a component of comprehensive pulmonary rehabilitation. IPPB devices were expensive and cumbersome. The superiority of IPPB devices over compressed air nebulizers was unknown. Accordingly, the NHLBI initiated the IPPB trial. ${ }^{1}$

A total of 985 participants at 5 centers were randomly assigned to either IPPB or compressed air nebulizer treatment. Entry criteria included symptomatic airflow obstruction with a pre-bronchodilator forced expiratory volume in 1 second $\left(F E V_{1}\right)$ to forced vital capacity $(F V C)$ ratio $<0.60$, a pre-bronchodilator $\mathrm{FEV}_{1}$ $<60 \%$ predicted, age $30-74$ years and ability to perform cycle ergometry. Participants were excluded if they had used IPPB for 1 month or longer within the preceding 6 months, were severely hypoxemic, or normalized their spirometry after inhaling isoproterenol.

The nebulizer that generated the aerosol was identical for both treatment arms. Both groups were prescribed 3 daily treatments with metaproterenol and were given background maintenance bronchodilation with theophylline or an oral beta-agonist. Over 3 years of treatment, participants had regular home visits and clinic-based measures of lung function, symptoms, and quality of life. Adherence to treatment was assessed by self-report and by use of electronic timers attached to the respiratory equipment. Spirometry was performed quarterly, and complete pulmonary function tests were performed annually. Exercise was tested with symptom-limited bicycle ergometry tests and functional status was evaluated with a modified Medical Research Council (mMRC) questionnaire. Mild dyspnea was defined as shortness of breath walking up steps or on an incline but not on level ground. Moderate dyspnea was breathlessness with routine daily activities and minimal exertion. Severe dyspnea was breathlessness at rest or with any activity.

The results of the study showed that there was no significant difference between the 2 treatment 
groups in terms of change in lung function, mortality, hospitalizations, or quality of life. There were no subgroups shown to benefit with one of the treatments. Despite the frequent home visits and unmasked objective measurements of adherence, participants took on average only about half of the prescribed treatments. ${ }^{2}$ Subsequent analyses revealed that higher socioeconomic status and greater disease severity were predictive of better adherence with treatments. The authors concluded: "We saw no advantage of IPPB over compressor nebulizer therapy in this large group of patients, and conclude that, if an advantage exists, it must be marginal."

Given the therapeutic similarity of the 2 treatment arms, the IPPB trial provided a well-characterized cohort of COPD patients with a wide range of severity. Thus, it provided many insights into the natural history of COPD that are consistent with current observations. ${ }^{3}$ The authors recognized that the postbronchodilator $\mathrm{FEV}_{1}$ was, by far, the best predictor of survival. Other less important predictors of poor survival included hyperinflation, tachycardia, impaired exercise capacity, and breathlessness. The decline in $\mathrm{FEV}_{1}$ was widely variable, but those with better $\mathrm{FEV}_{1}$ showed, on average, more rapid declines than those with advanced disease. Low body weight and poor nutritional status were also found to be indicative of poor outcomes. ${ }^{4}$ Taken together, these observations presaged the development of the widely adopted body weight-obstruction-dyspnea-exercise capacity score, (BODE) and age-dyspnea-obstruction (ADO) score for predicting survival in COPD. ${ }^{5,6}$ Moreover, the recognition that accelerated decline in $\mathrm{FEV}_{1}$ was associated with current smoking and was not a feature of late-stage disease, failed to support the FletcherPeto model of accelerating declines in lung function through the course of COPD. ${ }^{7}$

It has not been widely appreciated that the IPPB study made a concerted effort to obtain lung tissue from autopsied participants who died. This provided material from 46 autopsies for a series of structurefunctional correlations by Thurlbeck and colleagues over the next decade. ${ }^{8-13}$ Among many findings, these studies revealed that airway wall muscle thickness correlated with bronchodilator responsiveness and that mucus gland hyperplasia had a poor correlation with emphysema, supporting the dichotomization of COPD into chronic bronchitis and emphysema. Many of Thurlbeck's seminal observations have been reprised in the current literature using in vivo highresolution computed tomography (CT). ${ }^{14}$

This study, a comparative efficacy study, had a dramatic impact on the practice of respiratory therapy. Treatments with positive pressure breathing machines quickly became obsolete and were replaced by compressor driven nebulizers and hand-held metered dose inhalers. This study also raised awareness of the poor adherence with chronically prescribed inhaled medications, a condition that has changed little to the present day. The meticulous data collection methods employed in the IPPB trial provided information on the natural history of COPD that has been verified by numerous observational studies.

\section{Nocturnal Oxygen Treatment Trial}

Although oxygen supplementation with oxygen tents had been used in hospitals for hypoxemic patients with pneumonia and heart failure since 1798, the use of long-term domiciliary oxygen is relatively recent. The chronic use of oxygen in patients with COPD and hypoxemia was pioneered by Alvan Barach, MD, in the 1950s with the development of portable oxygen cannisters. ${ }^{15}$ Initial observational studies indicated that long-term oxygen in hypoxemic patients reduced dyspnea, increased exercise capacity, diminished pulmonary hypertension, and improved psychological function. ${ }^{16,17}$ The use of oxygen in the home for chronic use was gaining acceptance as practice in the 1960s, accelerated by the use of liquid oxygen and oxygen concentrators. Although many patients perceived improvement in their quality of life using long-term oxygen treatment, it was unknown how many hours of oxygen were needed to confer benefit and whether there was an improvement in survival. The United Kingdom Medical Research Council (MRC) initiated a trial in which participants were randomly allocated to either 15 hours of oxygen/day or no oxygen and early reports indicated an improvement in survival with oxygen. ${ }^{18,19}$ With concerns, therefore, that a nooxygen treatment group would be unacceptable, the NHLBI conducted the Nocturnal Oxygen Treatment Trial (NOTT) study that compared nocturnal oxygen treatment (12 hours) with continuous oxygen (24 hours/day). The inclusion criteria required severe resting room air hypoxemia, defined as an arterial positive pressure of oxygen $\left(\mathrm{PaO}_{2}\right)$ less than or equal 
to $55 \mathrm{~mm} \mathrm{Hg}$ or less than or equal to $59 \mathrm{~mm} \mathrm{Hg}$ with evidence of edema, polycythemia, or right atrial enlargement on an electrocardiogram The FEV $1 /$ FVC ratio had to be less than $70 \%$ after a bronchodilator with a normal or elevated total lung capacity and a clinical diagnosis of COPD. After screening more than 1000 patients, 203 participants at 6 centers were randomly assigned to the 2 treatment groups. Patients could use either oxygen concentrators, liquid oxygen, or compressed tanks at a flow rate that increased arterial oxygen by $6 \mathrm{~mm} \mathrm{Hg}$ or more and maintained a $\mathrm{PaO}_{2}$ of $60-80 \mathrm{~mm} \mathrm{Hg}$. Increases of $1 \mathrm{~L} / \mathrm{min}$ oxygen flow were made during sleep and with exercise. Adherence to oxygen use was measured by diaries and electronic timers attached to stationary oxygen delivery systems. The primary outcome measure was mortality, with secondary measures including neuropsychological function, pulmonary artery pressure, and hematocrit recorded. After 24 months of follow-up, the NOTT study showed that the mortality rate in the nocturnal oxygen group was nearly twice that of the continuous oxygen group (Peto odds ratio $=0.45$ [confidence interval 0.25-0.81]). Adherence to the assigned treatment was considered good with $80 \%$ of the continuous oxygen group using it for 14 or more hours per day and $80 \%$ of the nocturnal oxygen group using it less than 13 hours per day. In subgroup analysis, hypercapnic patients were particularly benefited by continuous oxygen: the $24-$ month case fatality rate was $46 \%$ with nocturnal only oxygen and $19.6 \%$ with continuous oxygen. Measurement of hemodynamic parameters by right heart catherization showed that the continuous oxygen group had improved stroke volume index, pulmonary vascular resistance and lower pulmonary artery pressure. $^{20}$ Neuropsychological function was slightly improved in patients on continuous versus nocturnal oxygen but this did not translate into benefits for quality of life. ${ }^{21}$

The NOTT study set the standard criteria for prescription of continuous oxygen that were adopted by payers including the U.S. Centers for Medicare and Medicaid Services (CMS). Patients who did not meet the NOTT entry criteria were not considered candidates for continuous oxygen although the trial did not test whether oxygen was effective in these individuals. It is remarkable that our current strong standards for use of oxygen are derived from a single trial of only 203 people, albeit consistent with the MRC results. Although the trial was small by today's standards, the meticulous care taken by the investigators and the incorporation of multiple outcome measures and the strength of the findings have not led to any serious challenges to the conclusions of this trial.

Several questions were left unanswered by NOTT whether patients with other lung diseases or with lesser degrees of hypoxemia would also benefit from oxygen. It would take more than 3 decades before these issues were partially addressed in the follow-up landmark trial - the Long-term Oxygen Treatment Trial (LOTT) which is described later in this review.

\section{Lung Health Study}

Previous major NHLBI-sponsored multisite clinical trials enrolled patients with well-established symptomatic disease. It was well-recognized, however, that many individuals who had evidence of airflow limitation were asymptomatic or had minimal, often dismissed symptoms of cough and phlegm. Physiologic studies of early involvement of small airways using sophisticated tests such as closing volume proved of limited value in establishing which cigarette smokers would develop COPD. ${ }^{22}$ Accordingly, there was an interest in identifying smokers who had minimal symptoms and testing whether early intervention with bronchodilators and smoking intervention could alter the trajectory of the disease. The theory was that reduction of airways hyperreactivity and repeated bronchoconstriction would alter airway remodeling in a manner analogous to treatment of asymptomatic systemic hypertension to prevent vascular remodeling.

Epidemiologic studies from Baltimore and Tucson demonstrated that the reduction in $\mathrm{FEV}_{1} / \mathrm{FVC}$ below a threshold of 0.7 was a strong predictor of subsequent decline in $\mathrm{FEV}_{1}$ whereas absolute $\mathrm{FEV}_{1}$ was not predictive. $^{23,24}$ Over a 2 -year period, 10 centers enrolled a total of 5887 current smokers aged 3560 years with an $F E V_{1} / F V C$ ratio of 0.7 or less and a FEV 1 between $55 \%-90 \%$ predicted. ${ }^{25}$ Participants were randomly assigned to 3 treatment arms: 1) Usual Care consisting of advice to quit smoking and referral to community resources; 2) Smoking InterventionPlacebo which consisted of a 12 session smoking cessation program and a 3-times daily placebo inhaler; 3) Smoking Intervention-Active (SIA) consisting of the smoking cessation program and inhalation of the bronchodilator ipratropium 3 times daily. ${ }^{26}$ The 
primary outcome of the trial was the 5-year decline in $\mathrm{FEV}_{1}$ measured with extensive quality control. ${ }^{27}$ The study showed that smoking cessation intervention had a significant benefit, largely during the first year of the study following smoking cessation and was greatest in those who did not relapse. The bronchodilator caused an initial and sustained improvement in $\mathrm{FEV}_{1}$, but this improvement disappeared after the bronchodilator was discontinued at the end of the study. ${ }^{28}$

The Lung Health Study (LHS) provided several important observations. First, it demonstrated that a state-of-the-art smoking cessation program that used freely available and prolonged nicotine replacement could have a major impact on smoking behavior. ${ }^{29}$ Moreover, those who quit smoking early showed improvement in their lung function and a reduction in lung function decline. Relapse to smoking was associated with an increased rate of decline. ${ }^{30}$ Thus, the LHS provided strong evidence that COPD casefinding among cigarette smokers and enrollment in a smoking cessation program could have a substantial impact on lung function over 5 years.

Another important observation was that airways reactivity to methacholine was common among participants with mild-to-moderate COPD who did not exhibit asthma symptoms and that the severity of airways reactivity predicted subsequent rates of $\mathrm{FEV}_{1}$ decline. ${ }^{31,32}$ Airways reactivity and subsequent decline in $\mathrm{FEV}_{1}$ was more prominent in women than men suggesting that there were gender differences in susceptibility to smoking. ${ }^{33}$ Continuing smokers with the greatest decline in $\mathrm{FEV}_{1}$ had the largest increment in airways reactivity over 5 years. ${ }^{34}$ In a subset of participants whose inhalers were connected to an electronic dose counting device, it was verified that self-report vastly over-estimated the actual inhaler use. Moreover, it was discovered that a substantial number of participants were "dumping" their inhalers by repetitive actuations just prior to a visit in order to appear adherent to the clinical team. ${ }^{35}$ This was the first large-scale use of electronic monitoring of inhalers which has become commonplace in modern bronchodilator trials.

Perhaps the most important outcome of the LHS was derived from the long-term passive follow-up of participants after they had completed the initial 5 years of the study. ${ }^{36}$ After an average follow-up of 14.5 years, those individuals who were originally screened and entered the 12-session smoking cessation program had an $18 \%$ reduction in mortality. Most of the adjudicated causes of death were due to lung cancer and cardiovascular disease which were greater in those who continued to smoke. This longterm outcome from the LHS is strong evidence that spirometric screening for COPD patients who are at high risk for smoking-related mortality and enrollment in a short-term structured smoking cessation program can have substantial long-term mortality benefits. It is anomalous, therefore that the U.S. Preventive Services Task Force has ignored the findings of the LHS trial in their decision to recommend against the use of spirometry screening in asymptomatic adult smokers. $^{37}$

\section{National Emphysema Treatment Trial}

Lung volume reduction surgery (LVRS), a surgical procedure to remove emphysematous regions of the lung was originally developed in the 1950s but was abandoned because of high mortality rates. ${ }^{38}$ The procedure was revived in the 1990s after a case series showed a remarkable $82 \%$ improvement in $\mathrm{FEV}_{1}$ and no surgical mortality or late mortality. ${ }^{39}$ The procedure was then widely adopted with more than 700 operations conducted in a 4-month period after Medicare issued a procedure code for reimbursement. The outcomes in the community were poor with a $26 \%$ mortality and high hospitalization use. ${ }^{40}$ Accordingly, the Healthcare Finance Administration partnered with the NIH-NHLBI to conduct a randomized clinical trial of LVRS, the National Emphysema Treatment Trial (NETT). The trial was subject to considerable political and ethical scrutiny but was launched in $1997 .{ }^{41,42} \mathrm{~A}$ total of 3777 patients were screened and 1218 were randomly assigned to either LVRS ( $n=608)$ or optimal medical management $(\mathrm{n}=610)$. Major enrollment criteria included CT evidence of bilateral emphysema with hyperinflation and air-trapping, and no other enumerated comorbidities that would constitute a contraindication to the surgery. All participants were required to complete a standardized pulmonary rehabilitation program and undertake a specified program of optimal medical management. ${ }^{43}$

Before the trial was completed, interim analyses indicated that a subgroup of patients who had low $F E V_{1}$ ( $<20 \%$ predicted) and either a low diffusing capacity ( $<20 \%$ predicted) or homogeneous emphysema were 
at particular risk for surgical mortality. This subgroup had a $16 \%$ surgical mortality with limited symptomatic benefit in those who survived surgery. ${ }^{44}$ This "highrisk" subgroup was therefore excluded from continuing in the trial, an unusual occurrence for a subgroup that was not pre-specified. ${ }^{45}$

At the end of the trial, the participants who were not in the high-risk subgroup had an acceptable $2.2 \%$ 30-day surgical mortality. At 90 days, the surgical group had significantly higher death rates with $5.2 \%$ mortality compared to $1.5 \%$ in the medical group. At 24 months, however, the surgical patients had a significantly greater probability of clinically meaningful improvements in exercise capacity and quality of life. Importantly, subgroups were identified who were most likely to benefit from surgery. In those with predominantly upper lobe emphysema and low exercise capacity, $30 \%$ showed an improvement in exercise capacity and $48 \%$ showed improvement in quality of life compared to $0 \%$ and $9 \%$ respectively in the medically treated arm. ${ }^{46}$ Participants were followed for survival for a median of 4.3 years, showing an overall better survival in the surgical group compared to the medical group despite the initially increased 30day surgical mortality (0.11 deaths/person-year versus 0.13 deaths/person-year, $P=0.02){ }^{47}$

Because the study was linked to Medicare funding, a rigorous cost-effectiveness analysis was conducted in parallel with the trial. ${ }^{48}$ This analysis showed that the cost per quality-adjusted life-year depended on the analytic timeframe. Because of the amortization of the large initial cost of surgery, the incremental costs were projected to fall over time. In the first year, the total costs for the medical group was $\$ 23,371$ compared to $\$ 71,515$ for surgery. After the initial post-surgical 6-month period, total health care costs in the surgical group were lower up to year 3 (\$36,199 versus \$49,628). This cost-saving was associated with fewer hospital days in the post-surgical group. The incremental cost-effectiveness ratio for LVRS was $\$ 190,000$ per quality-adjusted life year. However, over a 10-year timeframe this was projected to fall to an acceptable $\$ 53,000$ per quality-adjusted life year. For the high-benefit group with upper lobe disease and low exercise tolerance, the 10-year cost per qualityadjusted life year was $\$ 21,000$.

Based on the outcomes of the trial, Medicare issued a coverage decision that it would pay for LVRS in patients who met NETT criteria for clinical benefit, and who were treated in a designated center of excellence. Despite the evidence supporting the procedure, the number of patients referred for LVRS is now limited, perhaps because of the discordance between the initially promulgated expectations and the reality of the moderate benefits in a highly selected patient population. ${ }^{49,50}$ NETT also provided proof-of-concept that endoscopic non-invasive methods of lung volume reduction might be possible. ${ }^{51}$

With such a large and meticulously characterized and followed population, the NETT provided a wealth of information about the natural history, pathobiology, genetics, anatomy, clinical epidemiology and physiology of emphysema. These have been reviewed comprehensively. ${ }^{52}$ The surgical specimens from 159 patients were extensively evaluated by Hogg and colleagues providing detailed information about the role of mucus impactions, small airway disease and immune effector cells associated with emphysema outcomes. ${ }^{53,54}$ Genetic markers of emphysema were described that associated with emphysema score and disease progression. ${ }^{55,56}$ Predictors of surgical outcomes and surgical complications have been reviewed in detail. ${ }^{57}$

In summary, the NETT trial, one of the most complex and comprehensive clinical trials ever conducted in COPD, provided evidence that changed the practice of COPD treatment, saved millions of dollars in health care expenditures, prevented large numbers of ineffective or unnecessary surgery, and substantially increased the knowledge base about emphysema.

\section{Long-Term Oxygen Treatment Trial}

Although the treated population in the MRC trial and NOTT (see above) was small by today's standards, it provided strong evidence for a survival benefit in COPD patients with severe resting room air hypoxemia. Therefore, long-term oxygen has been considered the standard of care for such individuals. It was unknown whether patients with less than severe hypoxemia or those with exercise desaturation might benefit from tailored oxygen prescriptions. It has been common practice to prescribe oxygen for patients with exercise-induced desaturation. This practice has been supported by the Medicare coverage rules. Patients with moderate levels of hypoxemia that do not meet the NOTT criteria $\left(\mathrm{PaO}_{2}\right.$ above $55 \mathrm{~mm}$ 
$\mathrm{Hg}$ - or 55-60 mm Hg with evidence of complications) are not generally considered candidates for oxygen treatment. Two controlled trials have been published that have enrolled individuals with intermediate levels of hypoxemia. ${ }^{58,59}$ Neither study showed a survival benefit, but the trials were underpowered to exclude a mortality reduction. Supplemental oxygen in these patients have not shown consistently beneficial effects in terms of exercise capacity, symptoms, and quality of life. ${ }^{60-62}$ One observational study showed that oxygen prescriptions that did not comply with the Medicare guidelines was associated with an increased mortality. 63

Because the use of oxygen in COPD patients was considered an important gap in the evidence base for treating COPD, the NIH-NHLBI, in conjunction with the CMS, convened a workshop to review the cumulative evidence. ${ }^{64}$ Four clinical trials were recommended including one in patients with COPD and moderate levels of hypoxemia and one in patients with exercise induced hypoxemia. The Long-term Oxygen Treatment Trial (LOTT) addressed both issues. ${ }^{65}$ During the course of the trial, the study design was modified through a series of protocol amendments. Initially, only moderately hypoxemic patients were enrolled, but because of early difficulty in enrolling patients, the indication of exercise desaturation was added. The primary outcome was changed from mortality to a composite of hospitalization-free survival. Because the event rate for the primary outcome was anticipated to increase substantially, the sample size was reduced from 3108 to 1347 . After interim analyses showed better than expected adherence to treatment assignment, the sample size was further reduced to 737 . After screening 1759 participants, a sample of 738 were randomized to receive either no supplemental oxygen or a tailored oxygen prescription. Forty-seven clinics in 37 locations enrolled 1 or more patients into the trial. The tailored prescription was for 24-hour oxygen in those with resting moderate hypoxemia and oxygen during activity and sleep for those with exerciseinduced desaturation. Participants were followed for 1 to 6 years with a common close-out date and a median follow-up period of 18.4 months.

Results of the study indicated that oxygen prescriptions did not affect the primary outcome of time to hospitalization or death. ${ }^{66}$ Moreover, there was no discernable treatment effect on either of the components, or COPD-related hospitalization, quality of life or 6-minute walk distance. There were no subgroups that were demonstrably benefited by the oxygen treatment. Although these were highly consistent and statistically robust findings, there should be recognition that highly symptomatic patients may have refused to be randomized to the no oxygen group. Thus, based on this study, it is still a rational approach to offer moderately hypoxemic symptomatic patients a trial of oxygen supplementation with the understanding that it will not likely improve survival or reduce hospitalizations. If the individual patient does not have symptomatic improvement or objective evidence of improved exercise tolerance, then it is reasonable to discontinue the oxygen. ${ }^{67}$ In this regard, a subset analysis of LOTT participants indicated that a positive attitude toward the use of oxygen was associated with better adherence. ${ }^{68}$

\section{Summary}

These 5 landmark clinical trials have had a major impact on the care of patients with COPD. We no longer use positive pressure breathing machines to deliver bronchodilator aerosols. Continuous oxygen supplementation for severely hypoxemic patients is considered standard of care. Screening asymptomatic smokers for airflow obstruction and enrolling them in an effective smoking cessation program has potential for diminishing the disease impact and reducing COPD morbidity and mortality long into the future. Lung volume reduction surgery is now available to highly selected patients and we have a good understanding of patients who will not benefit from this procedure. Continuous oxygen in individuals with moderate resting hypoxemia or ambulatory oxygen for individuals with COPD who desaturate with exercise is no longer considered a mandatory treatment.

One of the major accomplishments of NHLBIsponsored landmark trials is the influence on standard procedures for conducting COPD clinical trials. Clinical trial methods that have been adapted or developed by NHLBI clinical trials have been widely accepted in research for COPD and related conditions. These procedures include:

- Criteria by which COPD is defined in clinical research, specifically the use of $\mathrm{FEV}_{1} / \mathrm{FVC}$ ratio less than 0.7 as a definition of airflow limitation. (LHS) 
- Quality control standards for spirometry using central review and comprehensive training and certification of technicians. (LHS)

- Standardization of lung volume measurements by body plethysmography. (NETT)

- The use of standardized computed tomographic quantitative densitometry and visual scoring as a clinical trial outcome. (NETT)

- Standardization of procedures for exercise desaturation testing. (LOTT)

- Standardization of optimalpulmonaryrehabilitation programs as a component of clinical trial treatment. (NETT)

- Development of methods for state-of-the-art smoking cessation interventions incorporating nicotine replacement. (LHS)

- Objective measures of adherence such as electronic inhaler dose counters, pill counters, oxygen and nebulizer use. (IPPB, NOTT, LHS, LOTT)
- Use of independent, masked mortality and morbidity review panels to assess cause of death and hospitalization. (LHS, NOTT, NETT)

- Comparative studies with active treatments where there was uncertainty about superiority of different treatments. (IPPB, LHS, NOTT)

- Integration of Medicare reimbursement for treatment in the context of clinical research. (NETT, LOTT)

- Incorporation of cost-benefit analyses into clinical trials (NETT)

The NIH, and the NHLBI and its Division of Lung Diseases, should be congratulated for their track record in initiating and sponsoring these trials.

\section{Declaration of Interest}

The authors have nothing relevant to declare. 


\section{References}

1. The Intermittent Positive Pressure Breathing Trial Group. Intermittent positive pressure breathing therapy of chronic obstructive pulmonary disease. Ann Intern Med.1983; 99(5):612620. doi: https://doi.org/10.7326/0003-4819-99-5-612

2. Turner J, Wright E, Mendella L, Anthonisen N. Predictors of patient adherence to long-term home nebulizer therapy for COPD. The IPPB Study Group. Intermittent Positive Pressure Breathing. Chest. 1995;108(2):394-400. doi: https://doi.org/10.1378/chest.108.2.394

3. Anthonisen NR, Wright EC, Hodgkin JE. Prognosis in chronic obstructive pulmonary disease.AmRev Respir Dis. 1986;133(1):1420. doi: https://doi.org/10.1164/arrd.1986.133.1.14

4. Wilson DO, Rogers RM, Wright EC, Anthonisen NR. Body weight in chronic obstructive pulmonary disease. The National Institutes of Health Intermittent Positive-Pressure Breathing Trial. Am Rev Respir Dis. 1989;139(6):1435-1438. doi: https://doi.org/10.1164/ajrccm/139.6.1435

5. Celli BR, Cote CG, Marin JM, et al. The body-mass index, airflow obstruction, dyspnea, and exercise capacity index in chronic obstructive pulmonary disease. N Engl J Med. 2004; 350 (10):1005-1012. doi: https://doi.org/10.1056/NEJMoa021322

6. Puhan MA, Garcia-Aymerich J, Frey M, et al. Expansion of the prognostic assessment of patients with chronic obstructive pulmonary disease: the updated BODE index and the ADO index. Lancet. 2009;374(9691):704-711.

doi: https://doi.org/10.1016/S0140-6736(09)61301-5

7. Vestbo J, Edwards LD, Scanlon PD, the ECLIPSE Investigators. Changes in forced expiratory volume in 1 second over time in COPD. N Engl J Med. 2011;365(13):1184-1192. doi: https://doi.org/10.1056/NEJMoa1105482

8. Nagai A, West WW, Paul JL, Thurlbeck WM. The National Institutes of Health Intermittent Positive-Pressure Breathing trial: pathology studies. I. Interrelationship between morphologic lesions. Am Rev Respir Dis. 1985;132(5):937-945.

9. Nagai A, West WW, Thurlbeck WM. The National Institutes of Health Intermittent Positive-Pressure Breathing trial: pathology studies. II. Correlation between morphologic findings, clinical findings, and evidence of expiratory air-flow obstruction. Am Rev Respir Dis. 1985;132(5):946-953.

10. West WW, Nagai A, Hodgkin JE, Thurlbeck WM. The National Institutes of Health Intermittent Positive Pressure Breathing trial-pathology studies. III. The diagnosis of emphysema. Am Rev Respir Dis. 1987;135(1):123-129.

11. Matsuba K, Ikeda T, Nagai A, Thurlbeck WM. The National Institutes of Health Intermittent Positive-Pressure Breathing Trial: pathology studies. IV. The destructive index. Am Rev Respir Dis. 1989;139(6):1439-1445.

doi: https://doi.org/10.1164/ajrccm/139.6.1439
12. Nagai A, Yamawaki I, Takizawa T, Thurlbeck WM. Alveolar attachments in emphysema of human lungs. Am Rev Respir Dis. 1991;144(4):888-891.

doi: https://doi.org/10.1164/ajrccm/144.4.888

13. Nagai A, Thurlbeck WM, Konno K. Responsiveness and variability of airflow obstruction in chronic obstructive pulmonary disease. Clinicopathologic correlative studies. Am J Respir Crit Care Med. 1995;151(3 Pt 1):635-639. doi: https://doi.org/10.1164/ajrccm/151.3_Pt_1.635

14. Bhatt SP, Washko GR, Hoffman EA, et al. Imaging advances in chronic obstructive pulmonary disease. Insights from the Genetic Epidemiology of Chronic Obstructive Pulmonary Disease (COPDGene) study. Am J Respir Crit Care Med. 2019;199(3):286-301. doi: https://doi.org/10.1164/rccm.201807-1351SO

15. Heffner JE. The story of oxygen. Respir Care. 2013;58(1):18-31. doi: https://doi.org/10.4187/respcare.01831

16. Levine BE, Bigelow DB, Hamstra RD, et al. The role of longterm continuous oxygen administration in patients with chronic airway obstruction with hypoxemia. Ann Intern Med. 1967;66(4):639-650.

doi: https://doi.org/10.7326/0003-4819-66-4-639

17. Petty TL, Finigan MM. The clinical evaluation of prolonged ambulatory oxygen therapy in patients with chronic airway obstruction. Am J Med. 1968;45(2):242-252.

doi: https://doi.org/10.1016/0002-9343(68)90042-9

18. Flenley DC, Douglas NJ, Lamb D. Nocturnal hypoxemia and longterm domiciliary oxygen in blue and bloated bronchitics. Chest. 1980;77:305-307. doi: https://doi.org/10.1378/chest.77.2.305

19. Report of the Medical Research Council working party. Longterm domiciliary oxygen therapy in chronic hypoxic cor pulmonale complicating chronic bronchitis and emphysema. Lancet. 1981;1:681-685.

doi: https://doi.org/10.1016/S0140-6736(81)91970-X

20. Timms RM, Khaja FU, Williams GW, and the Nocturnal Oxygen Therapy Trial Group. Hemodynamic response to oxygen therapy in chronic obstructive pulmonary disease. Ann Intern Med. 1985;102(1):29-36.

doi: https://doi.org/10.7326/0003-4819-102-1-29

21. Heaton RK, Grant I, McSweeny AJ, Adams KM, Petty TL. Psychologic effects of continuous and nocturnal oxygen therapy in hypoxemic chronic obstructive pulmonary disease. Arch Intern Med. 1983;143(10):1941-1947.

doi: https://doi.org/10.1001/archinte.143.10.1941

22. Buist AS, Vollmer WM, Johnson LR, McCamant LE. Does the single-breath N2 test identify the smoker who will develop chronic airflow limitation? Am Rev Respir Dis. 1988;137(2):293301. doi: https://doi.org/10.1164/ajrccm/137.2.293 
23. Burrows B, Knudson RJ, Camilli AE, Lyle SK, Lebowitz MD. The "horse-racing effect" and predicting decline in forced expiratory volume in one second from screening spirometry. Am Rev Respir Dis. 1987;135(4):788-793.

doi: https://doi.org/10.1164/arrd.1987.135.4.788

24. Beaty TH, Menkes HA, Cohen BH, Newill CA. Risk factors associated with longitudinal change in pulmonary function. Am Rev Respir Dis. 1984;129(5):660-667.

doi: https://doi.org/10.1164/arrd.1984.129.5.660

25. Durkin DA, Kjelsberg MO, Buist AS, Connett JE, Owens GR. Recruitment of participants in the Lung Health Study, I: Description of methods. Control Clin Trials. 1993;14(2 Suppl): 20S-37S. doi: https://doi.org/10.1016/0197-2456(93)90022-6

26. Connett JE, Kusek JW, Bailey WC, O’Hara P, Wu M. Design of the Lung Health Study: a randomized clinical trial of early intervention for chronic obstructive pulmonary disease. Control Clin Trials. 1993;14(2 Suppl):3S-19S.

doi: https://doi.org/10.1016/0197-2456(93)90021-5

27. Enright PL, Johnson LR, Connett JE, Voelker H, Buist AS. Spirometry in the Lung Health Study. 1. Methods and quality control. Am Rev Respir Dis. 1991;143(6):1215-1223.

doi: https://doi.org/10.1164/ajrccm/143.6.1215

28. Anthonisen NR, Connett JE, Kiley JP, et al for the Lung Health Study Research Group. Effects of smoking intervention and the use of an inhaled anticholinergic bronchodilator on the rate of decline of FEV 1 . The Lung Health Study. JAMA. 1994;272(19): 1497-1505.

doi: https://doi.org/10.1001/jama.1994.03520190043033

29. O’Hara P, Grill J, Rigdon MA, Connett JE, Lauger GA, Johnston JJ. Design and results of the initial intervention program for the Lung Health Study. The Lung Health Study Research Group. Prev Med. 1993;22(3):304-315.

doi: https://doi.org/10.1006/pmed.1993.1025

30. Scanlon PD, Connett JE, Waller LA, et al; Lung Health Study Research Group. Smoking cessation and lung function in mildto-moderate chronic obstructive pulmonary disease. The Lung Health Study. Am J Respir Crit Care Med. 2000;161(2 Pt 1):381390. doi: https://doi.org/10.1164/ajrccm.161.2.9901044

31. Tashkin DP, Altose MD, Connett JE, Kanner RE, Lee WW, Wise RA. Methacholine reactivity predicts changes in lung function over time in smokers with early chronic obstructive pulmonary disease. The Lung Health Study Research Group. Am J Respir Crit Care Med. 1996;153(6 Pt 1):1802-1811.

doi: https://doi.org/10.1164/ajrccm.153.6.8665038

32. Tashkin DP, Altose MD, Bleecker ER, et al. The lung health study: airway responsiveness to inhaled methacholine in smokers with mild to moderate airflow limitation. The Lung Health Study Research Group. Am Rev Respir Dis. 1992;145(2 Pt 1):301-310. doi: https://doi.org/10.1164/ajrccm/145.2_Pt_1.301
33. Kanner RE, Connett JE, Altose MD, et al. Gender difference in airway hyperresponsiveness in smokers with mild COPD. The Lung Health Study. Am J Respir Crit Care Med. 1994;150(4):956961. doi: https://doi.org/10.1164/ajrccm.150.4.7921469

34. Wise RA, Kanner RE, Lindgren P, et al; Lung Health Study Research Group. The effect of smoking intervention and an inhaled bronchodilator on airways reactivity in COPD: the Lung Health Study. Chest. 2003;124(2):449-458. doi: https://doi.org/10.1378/chest.124.2.449

35. Rand CS, Wise RA, Nides M, et al. Metered-dose inhaler adherence in a clinical trial. Am Rev Respir Dis. 1992;146(6):15591564. doi: https://doi.org/10.1164/ajrccm/146.6.1559

36. Anthonisen NR, Skeans MA, Wise RA, Manfreda J, Kanner RE, Connett JE; Lung Health Study Research Group. The effects of a smoking cessation intervention on 14.5-year mortality: a randomized clinical trial. Ann Intern Med. 2005;142(4):233-239. doi: https://doi.org/10.7326/0003-4819-142-4-200502150-00005

37. US Preventive Services Task Force (USPSTF), Siu AL, BibbinsDomingo K, Grossman DC, et al. Screening for chronic obstructive pulmonary disease: US Preventive Services Task Force recommendation statement. JAMA. 2016;315(13):13721377. doi: https://doi.org/10.1001/jama.2016.2638

38. Brantigan OC, Mueller E, Kress MB. A surgical approach to pulmonary emphysema. Am Rev Respir Dis. 1959;80:194-206.

39. Cooper JD, Trulock EP, Triantafillou AN, et al. Bilateral pneumectomy (volume reduction) for chronic obstructive pulmonary disease. J Thorac Cardiovasc Surg. 1995;109(1):106116. (discussion 116-119).

doi: https://doi.org/10.1016/S0022-5223(95)70426-4

40. Issues Relating to Medicare's Coverage Policy: Hearing Before the Subcommittee on Health of the House Committee on Ways and Means, 105th Cong, 1st Sess (1997) (testimony of Bruce C. Vladeck).

41. Wise RA, Drummond MB. The role of NEET in emphysema research. Proc Am Thorac Soc. 2008;5(4):385-392. doi: https://doi.org/10.1513/pats.200709-153ET

42. Wise RA. Ethical issues confronted in pulmonary clinical trials. Proc Am Thorac Soc. 2007;4(2):200-205. doi: https://doi.org/10.1513/pats.200701-006GC

43. The National Emphysema Treatment Trial Research Group. Rationale and design of the National Emphysema Treatment Trial: a prospective randomized trial of lung volume reduction surgery. Chest. 1999;116(6):1750-1761. doi: https://doi.org/10.1378/chest.116.6.1750

44. National Emphysema Treatment Trial Research Group. Patients at high risk of death after lung-volume-reduction surgery. $N$ Engl J Med. 2001; 345:1075-1083. doi: https://doi.org/10.1056/NEJMoa11798 
45. Lee SM, Wise R, Sternberg AL, Tonascia J, Piantadosi S; National Emphysema Treatment Trial Research Group. Methodologic issues in terminating enrollment of a subgroup of patients in a multicenter randomized trial. Clin Trials. 2004;1:326-338. doi: https://doi.org/10.1191/1740774504cn027oa

46. Fishman A, Martinez F, Naunheim K, et al; National Emphysema Treatment Trial Research Group. A randomized trial comparing lung-volume-reduction surgery with medical therapy for severe emphysema. N Engl J Med. 2003;348:2059-2073. doi: https://doi.org/10.1056/NEJMoa030287

47. Naunheim KS, Wood DE, Mohsenifar Z, et al. Long-term follow-up of patients receiving lung-volume-reduction surgery versus medical therapy for severe emphysema by the National Emphysema Treatment Trial research group. Ann Thorac Surg. 2006;82:431-443.

48. Ramsey SD, Berry K, Etzioni R, Kaplan RM, Sullivan SD, Wood DE; National Emphysema Treatment Trial Research Group. Cost effectiveness of lung-volume-reduction surgery for patients with severe emphysema. N Eng J Med. 2003;348:2092-2102. doi: https://doi.org/10.1056/NEJMsa030448

49. Ginsburg ME, Thomashow BM, Yip CK, et al. Lung volume reduction surgery using the NETT selection criteria. Ann Thorac Surg. 2011;91(5):1556-1560 (discussion 156). doi: https://doi.org/10.1016/j.athoracsur.2011.01.054

50. Stanifer BP, Ginsburg ME. Lung volume reduction surgery in the post-National Emphysema Treatment Trial era. J Thorac Dis. 2018;10(Suppl 23):S2744-S2747. doi: https://doi.org/10.21037/jtd.2018.05.135

51. Criner GJ, Sue R, Wright S, et al; LIBERATE Study Group. A Multicenter Randomized Controlled Trial of Zephyr Endobronchial Valve Treatment in heterogeneous Emphysema (LIBERATE). Am J Respir Crit Care Med. 2018;198(9):1151-1164.

52. Criner GJ, Cordova F, Sternberg AL, Martinez FJ. The National Emphysema Treatment Trial (NETT): Part I: Lessons learned about emphysema. Am J Respir Crit Care Med. 201;184(7):763770. doi: https://doi.org/10.1164/rccm.201103-0454CI

53. Hogg JC, Chu F, Utokaparch S, et al. The nature of small-airway obstruction in chronic obstructive pulmonary disease. $N$ Engl $J$ Med. 2004;350:2645-2653.

doi: https://doi.org/10.1056/NEJMoa032158

54. Hogg JC, Chu FS, Tan WC, et al. Survival after lung volume reduction in chronic obstructive pulmonary disease: insights from small airway pathology. Am J Respir Crit Care Med. 2007; 176(5):454-459.

doi: https://doi.org/10.1164/rccm.200612-1772OC

55. DeMeo DL, Hersh CP, Hoffman EA, et al. Genetic determinants of emphysema distribution in the National Emphysema Treatment Trial. Am J Respir Crit Care Med. 2007; 176(1):42-48. doi: https://doi.org/10.1164/rccm.200612-17970C
56. Hersh CP, DeMeo DL, Reilly JJ, Silverman EK. Xenobiotic metabolizing enzyme gene polymorphisms predict response to lung volume reduction surgery. Respir Res. 2007;8:59. doi: https://doi.org/10.1186/1465-9921-8-59

57. Criner GJ, Cordova F, Sternberg AL, Martinez FJ. The National Emphysema Treatment Trial (NETT) Part II: Lessons learned about lung volume reduction surgery. Am J Respir Crit Care Med. 2011;184(8):881-893. doi: https://doi.org/10.1164/rccm.201103-0455CI

58. G'orecka D, Gorzelak K, Sliwiński P, Tobiasz M, Zieliński J. Effect of long-term oxygen therapy on survival in patients with chronic obstructive pulmonary disease with moderate hypoxaemia. Thorax. 1997;52 (8):674-679.

doi: https://doi.org/10.1136/thx.52.8.674

59. Chaouat A, Weitzenblum E, Kessler R, et al. A randomized trial of nocturnal oxygen therapy in chronic obstructive pulmonary disease patients. Eur Respir J. 1999;14(5):1002-1008. doi: https://doi.org/10.1183/09031936.99.14510029

60. O'Donnell DE, D'Arsigny C, Webb KA. Effects of hyperoxia on ventilatory limitation during exercise in advanced chronic obstructive pulmonary disease. Am J Respir Crit Care Med. 2001;163(4):892-898.

doi: https://doi.org/10.1164/ajrccm.163.4.2007026

61. Emtner M, Porszasz J, Burns M, Somfay A, Casaburi R. Benefits of supplemental oxygen in exercise training in nonhypoxemic chronic obstructive pulmonary disease patients. Am J Respir Crit Care Med. 2003;168(9):1034-1042. doi: https://doi.org/10.1164/rccm.200212-15250C

62. Ringbaek T, Martinez G, Lange P. The long-term effect of ambulatory oxygen in normoxaemic COPD patients: a randomised study. Chron Respir Dis. 2013;10(2):77-84.

doi: https://doi.org/10.1177/1479972312473135

63. Drummond MB, Blackford AL, Benditt JO, et al. Continuous oxygen use in nonhypoxemic emphysema patients identifies a high-risk subset of patients: retrospective analysis of the National Emphysema Treatment Trial. Chest. 2008;134(3):497506. doi: https://doi.org/10.1378/chest.08-0117

64. Croxton TL, Bailey WC. Long-term oxygen treatment in chronic obstructive pulmonary disease: recommendations for future research: an NHLBI workshop report. Am J Respir Crit Care Med. 2006;174(4):373-378.

doi: https://doi.org/10.1164/rccm.200507-1161WS

65. Yusen RD, Criner GJ, Sternberg AL, et al; LOTT Research Group *; The Long-Term Oxygen Treatment Trial for chronic obstructive pulmonary disease: rationale, design, and lessons learned. Ann Am Thorac Soc. 2018;15(1):89-101. 
66. Long-Term Oxygen Treatment Trial Research Group, Albert RK, Au DH, Blackford AL, et al. Randomized trial of long-term oxygen for COPD with moderate desaturation. $N$ Engl J Med. 2016;375:1617-1627.

doi: https://doi.org/10.1056/NEJMoa1604344

67. Ekström M. Clinical usefulness of long-term oxygen therapy in adults. N Engl J Med. 2016;375(17):1683-1684.

doi: https://doi.org/10.1056/NEJMe1611742

68. Moy ML, Harrington KF, Sternberg AL, et al; LOTT Research Group. Characteristics at the time of oxygen initiation associated with its adherence: findings from the COPD Long-term Oxygen Treatment Trial. Respir Med. 2019;149:52-58.

doi: https://doi.org/10.1016/j.rmed.2019.02.004 